\title{
Inter-observer variation in habitat survey data: investigating the consequences for professional practice
}

\author{
by Andrew Cherrill
}

Copyright, Publisher and Additional Information: This is an Accepted Manuscript of an article published online by Taylor \& Francis in Journal of Environmental Planning and Management on 16 December 2015, available from:

DOI: $10.1080 / 09640568.2015 .1090961$

\section{A note on versions:}

The version presented here may differ from the published version or, version of record, if you wish to cite this item you are advised to consult the publisher's version.

Please note that access may require a subscription. 
Inter-observer variation in habitat survey data: investigating the consequences for professional practice

Andrew Cherrill

Crop and Environment Sciences

Harper Adams University

Edgmond

Shropshire

TF10 8NB

acherrill@harper-adams.ac.uk

Key words: observer bias, data error, vegetation mapping, environmental assessment Running title: Consequences of inter-observer variation 


\section{Abstract}

Environmental assessments and land use planning require reliable information on the botanical composition and distribution of habitats. There have been numerous academic studies of inter-observer variation in species-inventory and habitat mapping, but studies addressing the prevalence of inter-observer variation and consequences of poor quality data in professional practice are lacking. This paper addresses these questions via a questionnaire survey of environmental professionals using the standard Phase 1 and National Vegetation Classification (NVC) survey methods in the United Kingdom. The survey revealed that misidentification of habitat types within survey reports was relatively common (approximating to $20 \%$ of all reports seen by respondents over the previous five years). Approximately $40 \%$ of respondents who had encountered erroneous reports stated that these had led to inaccurate initial site ecological assessments. Additional field surveys and discussions with surveyors were commonly used to resolve these issues, but for Phase 1 and NVC $26 \%$ and $34 \%$ of respondents respectively had encountered one or more cases where errors resulted in negative consequences for clients commissioning surveys (in terms of extra costs and project delays). Net loss of biodiversity arising from inaccurate reports was reported in at least one instance by $32 \%$ and $38 \%$ of respondents for Phase 1 and NVC surveys respectively - results that may contribute to the attrition of natural capital within the UK. The study highlights the need to extend studies of inter-observer variation to consider impacts on environmental assessments and decision-making in professional practice. The potential benefits of introducing an accreditation scheme (favoured by the majority of respondents to the questionnaire) are discussed. 


\section{Introduction}

Knowledge of the extent and distribution of vegetation types is essential to underpin conservation assessments, land use planning and management of wildlife populations (Hill et al. 2005; IEEM 2006; Morris and Therivel 2009). Despite improvements in remote sensing of land cover, field survey remains an essential method for collection of data on the distribution of habitats and their floristic composition (IEEM 2006). Surveying of vegetation is recognised as a key skill required by ecologists and environmental managers (IEEM 2011), but studies of variability between surveyors have often revealed significant levels of disagreement in terms of the plant species and habitats recorded (e.g. Scott and Hallam 2003; Milberg et al. 2008; Stevens et al. 2004; Hearn et al. 2011). For example, a study using the National Vegetation Classification (NVC) in the UK found that pairwise spatial agreement between seven surveyors mapping vegetation at the same site averaged only $34 \%$ at the community level (Hearn et al. 2011). Comparisons between plant species lists drawn up by different surveyors working in the same plots typically show agreement in the range of $50 \%-70 \%$ for a variety of habitats (Scott and Hallam 2003). Professionals working in the environmental and conservation sectors are therefore aware of the potential for inter-observer variation and its impact on data quality, but there is a dearth of information on the extent to which it is perceived to be an impediment to good decision making in practice (Cherrill 2013a). If interobserver variation causes few problems then the issue may be largely irrelevant in day-to-day practice. However, if inter-observer variation in interpretation of habitat types is a cause of disagreement and poor decision-making there may be a mandate to change training and/or survey methods.

The focus of the present study is inter-observer variation in habitat mapping using two of the standard classifications in the United Kingdom, namely the Phase 1 habitat classification (JNCC 1993) and the National Vegetation Classification (NVC) (Rodwell 2006). Studies focussing on these methods have revealed spatial agreement between surveyors using the same method at the same site in the range of $25 \%$ to $70 \%$ (Cherrill 
2013a). These studies, however, were conducted either as bespoke academic research projects designed to directly assess observer variation (Cherrill and McClean 1995, 1999a, 1999b, 2000, 2001; Hearn et al. 2011) or as part of Quality Assurance procedures within a large-scale national monitoring programme designed to detect landscape change (Stevens et al. 2004). The extent to which these results are representative of inter-observer variation in professional practice involving environmental assessment and site management planning is therefore unknown (Cherrill 2013a). None the less, it can be hypothesised that errors made in identifying vegetation types in these spheres of activity may be frequent and that there may be consequences for conservation assessments, site management and planning decisions.

The present paper uses a questionnaire survey of members of the Chartered Institute of Ecology and Environmental Management (CIEEM) in the United Kingdom to address two main questions. First, how frequently are errors in data detected in reports describing the results of vegetation surveys? Second, what are the practical consequences of these errors? CIEEM has approximately five thousand members in the UK. They are ideally placed to respond to these questions being employed primarily in environmental consultancy, planning authorities, governmental environmental agencies, and non-governmental conservation organisations. The Phase 1 and NVC survey methods are used only in the UK, but similar approaches are used elsewhere (Alexander and Millington 2000). The wider applicability of the study is, therefore, to illustrate the need to extend academic studies of inter-observer variation to investigate their relevance to the day-to-day experiences of environmental professionals. The implications for further research and development of professional practice are discussed.

\section{The survey methods - background information}

To provide a background to the questionnaire survey, this section gives a brief overview of the Phase 1 and NVC methods and the types of survey errors commonly encountered.

\subsection{Phase 1 survey}

The Phase 1 method is a survey technique, and associated land cover classification, for the rapid mapping and preliminary ecological appraisal of semi-natural habitats (JNCC 1993; Hill 
et al. 2005). It has been used to map the extent and distribution of vegetation types within National Parks, but is also widely used in the scoping stage of Environmental Impact Assessment (EIA) and for other Preliminary Ecological Appraisals (PEA) of smaller areas such as nature reserves and sites subject to development (IEA 1995; IEEM 2006; Morris and Therivel 2009). Surveyors record parcels of homogenous vegetation on an Ordnance Survey base map of 1:10,000 scale whilst walking across the site (although this process can be supplemented by the use of aerial photographs before or during the site visit). Allocation of a parcel to mapping classes is conducted in the field and relies on the expertise of the surveyor to recognise key plant indicator species which reveal environmental conditions (e.g. soil pH) and land management activity (e.g. species indicative of sown nutrient rich improved grassland). Direct observation of environmental and management factors such as soil type, agricultural practices, hydrological flow regime and land use also play an important role in defining the habitat (which might better be termed land cover). The Phase 1 manual includes a description of each land cover type and the surveyor must allocate each parcel to the type which it most closely resembles (JNCC 1993). The process relies heavily on the experience and expertise of the surveyor in terms of both delineating homogenous parcels of vegetation and assigning each parcel to a mapping class.

The map is supplemented by spatially-located notes (known as Target Notes). Target Notes are marked with a numbered dot on the map and these link to detailed information in the survey report. Information may include lists of key indicator species, observations on site management, a preliminary conservation assessment, the need for further survey, and comment on any difficulties encountered in the classification process (JNCC 1993; Cherrill and McClean 1999a; Hill et al. 2005).

\subsection{National Vegetation Classification}

The NVC vegetation types are defined by phytosociological tables detailing their species composition (Rodwell 1991-2000; 2006). To conduct a field survey using the NVC, the surveyor must first define and map homogenous stands of vegetation whilst in the field. As with Phase 1 this process is subjective, but may be aided by the use of aerial photographs. 
Detailed floristic data is recorded from within the stand - ideally using a series of quadrats of a size recommended for the specific habitat (Rodwell 2006). The floristic data include estimates of both cover abundance (within quadrats) and frequency of occurrence (proportion of quadrats occupied) for each species. Stands are then allocated to a vegetation type within the NVC using a combination of traditional keys (Rodwell 1991-2000), computer based keys (Hill 1996; Malloch 1998), and professional judgement. Professional judgement utilises additional information on the environmental and management conditions with which vegetation types are associated, combined with a knowledge (albeit incomplete) of their geographic distributions (Rodwell 2006). The classification process may be completed in the field or, based on detailed quadrat and field notes, may be conducted retrospectively in the office.

The areas mapped using the NVC are generally smaller than those in Phase 1 surveys because of the requirement for detailed floristic data. The NVC is often used where vegetation worthy of more detailed investigation is noted in a preliminary Phase 1 survey. As with Phase $1, \mathrm{NVC}$ surveys are used in site management planning, conservation assessments and ecological aspects of EIA in the UK (Hill et al. 2005; IEEM 2006; Morris and Therivel 2009).

\subsection{Types of survey error associated with Phase 1 and NVC survey data}

The causes of errors in Phase 1 and NVC survey have been investigated previously using case studies (Cherrill and McClean 1995, 1999a, 1999b, 2000, 2001; Stevens et al. 2004; Hearn et al. 2011). The overall average repeatability of mapping decisions within studies varied from $25 \%$ to $70 \%$ (Cherrill 2013a), although this figure differed between vegetation types. Unmodified habitats and those with similar species composition were most frequently confused (Cherrill and McClean 1995, 1999b; Hearn et al. 2011). For example, Stevens et al. (2004) found an average spatial agreement of $56 \%$ for semi-improved grasslands, but an average of $88 \%$ for highly modified habitats (such as arable cultivation and amenity grasslands). Spatial errors in the location of vegetation boundaries occur, but eliminating these typically improves agreement between pairs of maps by less than 10\% (Cherrill 2013a). 
Misclassification of vegetation types is by far the greatest cause of errors for both methods suggesting that differences between surveys arise primarily because of inter-observer variation in how the vegetation is perceived (e.g. which species are present and how abundant they are) and how this information is processed to allocate a stand of vegetation to a mapping class. Contributory factors appear to be 'fuzzy' boundaries between vegetation types within the classifications (a particular issue for Phase 1), the inherent complexity of vegetation continua encountered in the field, and inter-observer variation in the spatial resolution and rigour of field data collection (often related to underlying differences in surveyor experience and botanical identification skills) (Cherrill and McClean 1999a, 1999b; Hearn et al. 2011, Cherrill 2014).

\section{Methods}

An online questionnaire was selected as the most effective way of obtaining a sample of responses from the membership of CIEEM who are spread throughout the UK among a wide range of employers. A questionnaire was also favoured over case studies, focus groups or interviews because it allowed respondents to remain anonymous. Anonymity was an important issue because raising concerns with the quality of the work of other professionals can be an uncomfortable experience. Inevitably there is a risk of a self-selection bias in this approach with members who had encountered poor quality surveys being more likely to respond. Characteristics of the respondents were, however, retrospectively compared to the full membership and found to be broadly representative in terms of employment sector, geographical location and membership grade (Table 1).

An issue in the application of a questionnaire to determine perceived levels of classification errors in survey reports is knowing whether they have been judged fairly. It was not practical for the author to visit the sites or view survey reports. Moreover, studies of interobserver variation suggest that addition of an extra opinion does not necessarily lead to greater agreement (Cherrill and McClean 1999a; Hearn et al. 2011). It is possible that in some cases those interpreting the survey reports as being inaccurate were actually wrong. In terms of estimating levels of inter-observer variation this distinction is unimportant because in either 
scenario it is apparent that a difference of opinion existed. Knowing which view was correct is, however, desirable in determining how we should treat the respondents' views about the causes of the perceived 'error' (and particularly where the respondent identifies aspects of the other surveyor's behaviour or training as a contributory factor). Identifying the underlying causes of inter-observer variation is not the focus of the present paper (but see Cherrill 2014). Similar caveats do, however, apply to respondents' views on the consequences of survey errors on biodiversity. Where the ecological value of a site is in dispute its subsequent loss has different interpretations depending on your viewpoint. This caveat needs to be borne in mind with regard to interpretation of the responses relating to impacts on biodiversity.

\subsection{Questionnaire design}

Questions were formulated based on the author's experience conducting a series of studies focussing on inter-observer variation (Cherrill \& McClean 1995, 1999a, 2013a) and engagement with members via an online discussion thread on a social networking site (Cherrill 2013b). Three drafts of the questionnaire were each piloted with up to 25 members of CIEEM representing a diversity of employment sectors. Feedback was used to refine the questions. The final questionnaire was designed to be completed within 20 to 30 minutes. Preliminary questions in the final questionnaire asked respondents to identify their CIEEM membership grade, main country of employment and sector of employment. Members were then asked sets of identical questions about each of the two survey methods. A specific question focussed on the frequency, during the last five years, with which respondents had encountered survey reports in which they believed that there were errors in classification of vegetation types. Options were Never, Rarely ( $<10 \%$ of reports), Frequently (10-33\% of reports), Often (33-66\% of reports), Most cases (66-99\% of reports), or Always ( $100 \%$ of reports). Respondents who had encountered at least one report containing misidentification of vegetation types were then asked to estimate the frequency of each of five potential consequences using a scale of Never, In Some Cases, or Always. The consequences scored were: "Discussion with the surveyor was required to resolve the issues"; "Further field survey was required to resolve the issues"; "There were negative impacts for my organisation 
(e.g. additional costs and time lost)"; "There were negative consequences for my clients/partners (e.g. delays in project schedules and additional costs)"; and "There were negative consequences for biodiversity (e.g. a net loss of valued species and habitat)". Respondents completing these closed-questions were then invited to provide further detail within open-text boxes on a) the reason why the survey(s) were conducted, b) the consequences of the perceived errors, c) the likely causes of the errors in reports, and d) beneficial modifications to the current survey methodologies. Respondents were free to write as little or as much as they wished up to a maximum of 100 words. Throughout the questionnaire respondents could decline to answer individual questions. Relatively few respondents completed open-text boxes for questions c) and d). Moreover, these open-text questions were not preceded by closed questions (which tended to elicit a much higher response rate) and consequently these data are not reported here (but see Cherrill 2014 for an overview).

A final closed question asked all respondents to state if they were in favour of establishment of an accreditation scheme for surveyors carrying out Phase 1 and NVC surveys.

\subsection{Dissemination of the questionnaire}

The questionnaire was actively disseminated to members of CIEEM by staff in the organisation's head office. The questionnaire was promoted through an article in CIEEM's inhouse magazine, via emails to members, and a group established on an online social networking site for environmental professionals (Cherrill 2013b). The questionnaire was accessed via a weblink and available online between early December 2013 and the end of January 2014.

\subsection{Analytical approach}

Analysis took two approaches. Responses to closed-questions were tallied and are presented as a percentage of the respondents answering each question. Written comments in the open text boxes were systematically examined by the author to identify common themes. Responses within themes were tallied to give an indication of their relative importance. 
Representative examples of written responses to the open-text box question on the consequences of errors were selected for inclusion in this paper to illuminate the analysis.

Preliminary statistical analyses revealed that country, type of employment and membership grade had no statistically significant effects in terms of which questions were answered or the frequency with which data errors were reported. Data from all respondents have therefore been pooled.

\section{Results}

\subsection{Characteristics of respondents}

A total of 157 respondents completed the questionnaire with 148 and 88 answering questions about Phase 1 and NVC respectively. All but two respondents were members of CIEEM with the majority being Full members working in England as environmental consultants (Table 1). Members completing the questionnaire were relatively well-qualified compared to the full membership and were likely to have had a wider range of relevant experience. It is possible that members who had encountered errors in survey reports were more likely to respond to the questionnaire, but the extent of this bias cannot be assessed. Overall, there was a broad concordance between the profile of respondents and the full membership of CIEEM (Table 1).

\subsection{Frequency of reports containing errors}

Figure 1 shows the proportion of survey reports which respondents perceived to contain errors in identification of vegetation types. The overall patterns were similar for Phase 1 and NVC, although marginally fewer problems were perceived with the latter. Overall, at least $56 \%$ and $45 \%$ of respondents had encountered errors in more than $10 \%$ of survey reports using Phase 1 and NVC respectively (Figure 1). Few respondents had never encountered errors in survey reports using the Phase $1(5 \%)$ or NVC $(15 \%)$ methodologies, but equally few reported errors in more than two-thirds of reports (Figure 1). The median response was in the Frequent (10$33 \%$ of surveys) category for Phase 1 surveys and the Rare category (up to $10 \%$ of surveys) for NVC. Taking a weighted average (using the mid-point of each ordinal category) suggests that approximately $20 \%$ and $18 \%$ of Phase 1 and NVC survey reports respectively contained errors. 


\subsection{The contexts of reports}

Phase 1 was primarily used during Preliminary Ecological Appraisals (PEA) of sites subject to development, both outside and within Ecological Impact Assessment (EcIA) as part of Environmental Impact Assessment (EIA) (Table 2). The most frequent types of development mentioned were wind turbines, housing, mineral extraction and changes in agricultural land use. Responses for Phase 1 survey also included cases (5\% of total) focussing on actual (or candidate) designated sites (typically sites of local conservation importance), resource inventory through large-scale mapping of habitats (5\%) and surveys feeding into site management plans (7\%). The NVC had an overlapping, but more diverse range of uses, notably in site management planning (27\%), post-development monitoring (5\%) and surveys of designated sites (14\%) (typically sites of national conservation importance) (Table 2).

\subsection{The consequences of errors}

For both survey methods, over $25 \%$ of respondents reported that errors in habitat classification were always resolved successfully through discussion with the surveyors (Table 3). This was also true in at least some cases for a further $56 \%$ and $59 \%$ of respondents for Phase 1 and NVC respectively. Fewer respondents always relied on follow-up field surveys to resolve issues, but further field survey using both methods was conducted in at least some cases by over $70 \%$ of respondents (based on the sum of the columns headed 'In some cases' and 'Always' in Table 3).

Over half of respondents reported that poor quality Phase 1 and NVC surveys had impacted negatively on their own organisations, through the need to spend additional time and money, in at least some cases. It appears that this burden was shouldered primarily by the respondents to the questionnaire rather than their clients (and other partners) with whom they were working. For each method, approximately $56 \%$ of respondents stated that clients and partners never suffered any negative consequences. Similarly more than 52\% (for Phase 1 surveys) and $45 \%$ (for NVC surveys) stated that errors never resulted in negative consequences for biodiversity. Negative outcomes, however, for clients/partners (in terms of additional costs and delays) were experienced by $26 \%$ and $34 \%$ of respondents in at least 
some cases for Phase 1 and NVC respectively (based on summation of the columns headed 'In some cases' and 'Always' in Table 3). Similar estimates for biodiversity indicate negative impacts were noted by approximately $32 \%$ and $38 \%$ of respondents for Phase 1 and NVC surveys respectively (Table 3).

\subsection{Responses to the open-question on the consequences of errors}

The percentages of respondents reporting consequences in the open-text box under four main themes are shown in Table 4. These data have two limitations. First, relatively few respondents completed the open-text box question. Second, those respondents who did use the open-text box typically wrote about only one or two consequences, rather than the full range highlighted in the structured closed-questions. These factors make direct comparison with the data based on the more assiduously completed closed-questions in Table 3 difficult.

Nonetheless, the responses to the open-question do provide an additional level of insight and richness that numbers alone cannot. An important insight from the open-question was that over $40 \%$ of respondents believed inaccurate values were placed on sites where reports contained classification errors (Table 4). This response was not an option in the closedquestions and would otherwise have gone undetected.

Inaccurate site assessment has the potential to lead to poor impact prediction, inappropriate mitigation and poor project design decisions. However, in the open-question these consequences were each reported explicitly by less than $10 \%$ of respondents who had encountered reports containing misidentification of vegetation types (Table 4). This was presumably because the errors were usually corrected before these more serious outcomes could arise. Ultimately poor mitigation could lead to loss of biodiversity. This was reported by around $6 \%$ of respondents in the open-text box (Table 4), yet over $30 \%$ of respondents reported this had occurred in at least one instance based on the structured closed-questions (Table 3). The discrepancy is probably due to a combination of low response rate to the openquestion and a reluctance to write unprompted about more than one or two impacts.

\subsubsection{Accuracy of site assessments}


Analysis of responses in open text box explicitly revealed that inaccurate site assessments were caused by errors in classification of the vegetation. For example:

When working with third party data, that the habitats had been under or over valued as a result of third party habitat classifications. (Phase 1)

Species rich unimproved/semi-improved grasslands have been mistaken as having no/low biodiversity interest (i.e. habitat identified as species poor grassland). (Phase 1)

This [habitat miss-identification] can mean that presence of significant habitats cannot be proven conclusively, which impacts application of the legislation. (NVC)

It is important to recognise that the statements above refer to cases where the inaccurate site assessments were detected by respondents checking survey reports. Thus, the potential for further consequences was reduced through remedial actions including discussions with the surveyors and further field survey. These points are illuminated in the following themes.

\subsubsection{The need for further field survey}

Responses to open text box question illustrate the additional time, financial cost and frustration resulting from the need for further survey to resolve issues of vegetation misclassification:

The main consequences were that as an experienced surveyor I had to re-classify the habitats correctly. (Phase 1)

We had to resurvey the sites. If robust NVC surveys had been done originally the follow up survey would have taken less time and financial outlay. (NVC)

Report didn't really make sense in terms of the plant community described and the management regime; site was re-surveyed as a consequence. (NVC)

In many cases respondents' attributed problems to the inexperience of the surveyors, for example:

......Lack of botanical knowledge of the surveyor, poor attention to detail, poor understanding of ecological structure and function of habitat, poor evaluation. (Phase 1)

Incorrect species identification, particularly for difficult species groups. Some surveyors are not always qualified to carry out the work. (NVC) 
There are far too many inexperienced consultants with woeful botanical skills (not really even up to scratch to carry out a competent extended Phase 1 survey) that just can't identify the key species that make up the relevant habitat communities. (NVC)

\subsubsection{Additional time required for discussion and revision of reports}

A frequent response to both closed- and open-questions was that respondents invested additional time to resolve survey issues and rewrite reports (Tables 3 and 4):

Usually resolvable by discussion or sensible interpretation (if external to our organization) - often small changes to reports to better acknowledge uncertainties, abnormalities etc. (Phase 1)

A particular feature of the NVC is that it is based on quantitative estimates of the abundance of plant species obtained from quadrats. A number of respondents explicitly identified the need to spend extra time on further analysis of this data:

Major consequences are usually expenditure of time on disentangling data. (NVC)

\subsubsection{Unavoided negative outcomes}

Overall, the quantitative and qualitative data in Tables 3 and 4 indicate that further field work and discussions with surveyors typically circumvented more serious negative consequences (e.g. loss of biodiversity). Several comments explicitly reported this outcome:

No consequences because further survey ensured accurate evaluation. (Phase 1)

Consequences were limited as a Quality Assurance of the results allowed anomalies to be identified. (NVC)

However, a range of negative consequences could not be avoided. Committing extra time to confirmatory field surveys, additional discussion with surveyors and clients, and revising survey reports have inevitable financial costs. For example:

My company is dealing with resurvey of at least two proposed development sites. Often this is done anyway, but as the original surveys were lacking, it will take much time and financial outlay. (Phase 1)

Avoidance of delays for clients was not always possible. In a small number of cases the need for discussion and further field work lead to delays in the development planning process: 
Additional surveys required, either prompted by internal review or Local Planning Authority ecologist, with unexpected delays for developer. (Phase 1)

Time delay to resolve the issue and granting of planning permission. (NVC)

Misidentification of habitats and consequent inappropriate valuation of sites subject to development contributed to a failure to identify significant impacts, inappropriate mitigation measures and biodiversity loss in at least some cases. For example:

..... unfortunately planning applications being given the go ahead based on misleading (wrong) biodiversity information, and the habitat/species being permanently lost, and destroying the biodiversity value of the site. (Phase 1)

Inaccurate evaluation and identification of site habitats, leading to poor decisions relating to development avoidance and mitigation, enhancement and mitigation. (NVC)

Overall, given the range of negative impacts identified it is interesting that only one respondent commented on the potential for reputational damage to the individuals undertaking and reporting ecological surveys (Table 4).

\subsection{Support for an accreditation scheme}

There was broad support among respondents for the development of accreditation schemes for surveyors undertaking both Phase 1 (77.3\% in favour, $\mathrm{n}=110)$ and NVC (84.4\% in favour, $\mathrm{n}=77$ ) surveys.

\section{Discussion}

Vegetation mapping underpins many environmental assessment and decisions made by site managers and land use planners. It is well-known that inter-observer variation can undermine the quality of this data but the frequency with which this occurs, and the resultant consequences, in day-to-day professional practice has rarely been subject in investigation (Cherrill 2013a). The present study revealed that the most frequent immediate consequence of poor quality Phase 1 and NVC data was that inaccurate assessments were made about the ecological value of sites (Table 4). Although these were typically corrected through discussions with the surveyor and further field work, this represented a significant use of time, finance and effort and hence has negative impacts on the individuals and bodies involved. 
Moreover, there were cases where avoidable losses of biodiversity and delays to projects occurred because decisions were based on data that subsequently proved to be unreliable (Table 3 and 4). Over the five year period up to early 2014, a net loss of biodiversity attributed to inaccurate evaluations, based on erroneous survey reports, was reported in at least one instance by $32 \%$ and $38 \%$ of respondents for Phase 1 and NVC respectively. However, whether the attribution of these impacts solely to weaknesses in ecological data is truly justifiable is impossible to assess. A myriad of factors influence land management decisions (Glasson et al. 2012) and ecological considerations may not have been paramount in all of these cases. Nonetheless, the planning process in the UK has been criticised for its failure to adequately account for ecological impacts (Treweek et al. 1993; Thompson et al. 1997; Treweek and Thompson 1997; Gray and Edwards-Jones 1999; Byron et al. 2000; Drayton and Thompson 2013) and the present study suggests that at least some of this failure may reflect issues with the quality of survey reports submitted with planning applications.

The concerns revealed here have general applicability beyond habitat mapping surveys. Inter-observer variation is a ubiquitous feature of ecological survey and has probably been most extensively documented for botanical surveys, but has also been documented for survey of the physical characteristics of river channels (Angold et al. 1996, Gurnell et al. 1996), land management impacts on upland vegetation (MacDonald 2010) and a range of taxa including birds (Diefenbach et al. 2003; Frederick et al. 2003; Farmer et al. 2012), bats (Westcott and Mckeown 2004; Fritsch and Bruckner 2014), freshwater and marine fish (Garcia-Vazquez et al. 2012; Bernard et al. 2013), freshwater diatoms (Besse-Lototskaya et al. 2006; Kahlert et al. 2012), freshwater macroinvertebrates (Hasse et al. 2006, 2010), amphibians (Lotz and Allen 2007; Pierce and Gutzwiller 2007; McClintock et al. 2010), marine mammals (Hobbs and Waite 2010), terrestrial mammals (Jenkins and Manly 2008; Molianari-Jobin et al. 2012; Meek et al. 2013; Sunde and Jenkins 2013) and aquatic molluscs (Shea et al. 2011). A characteristic of these studies is that while some suggest improvements to survey methodology, few explore the frequency of observer variability in day-to-day professional practice, or investigate their consequences beyond the confines of the study. An 
exception are those focussing on ecological water quality assessments conducted to meet the requirements of the EU Water Framework Directive (WFD). The WFD requires levels of uncertainty, including those caused by observer error, associated with the classification of rivers into five ecological status classes to be reported (Furse et al. 2006; Environment Agency 2009a, 2009b). A wide range of metrics derived from ecological surveys are used and, while most are robust, a proportion have been shown to be susceptible to error caused by inter-operator variation (e.g. Kelly 1997; Clarke and Hering 2006; Hasse et al. 2010; Staniszewski et al. 2006; Kahlert et al. 2012; Thackeray et al. 2013; Kolada et al. 2014). Further research should focus on these issues in other areas of ecological assessment and will require the involvement of ecologists and environmental managers in professional practice ideally facilitated through collaborations with industry professional bodies such as CIEEM. The present study demonstrates that a questionnaire survey can generate useful information, but the approach is not without difficulties. The use of a combination of closed- and openquestions generated complementary information. The latter yielded insights which would otherwise have been lost, but estimates of the proportion of respondents witnessing loss of biodiversity differed markedly depending on which type of questions was used (6\% versus $>30 \%$ ) (Tables 3 and 4). The closed-question on biodiversity impacts generated the higher estimate and is probably more reliable because of its narrower focus and higher response rate. Investigation of inter-observer variation in professional practice is not easy. Ecological surveys are not routinely repeated unless problems with an initial survey are detected or suspected. Inter-observer variation therefore manifests itself in situations where a survey report leads to a disagreement about the habitats and species actually present (Cherrill 2013b). Workers may be reluctant to openly discuss concerns about perceived weaknesses in colleagues' work. Such concerns may therefore be raised only when there are potentially serious outcomes. Disagreement about the classification of a habitat, where both alternatives are recognised as being of negligible conservation value may not warrant comment. For example, studies of Phase 1 survey have shown that the floristically similar Poor semiimproved grassland and Improved grass are frequently confused (Cherrill and McClean 
1999b). The results of the present questionnaire survey may therefore underestimate the overall level of classification errors in Phase 1 and NVC reports due to a tendency to underreport trivial errors which were deemed unimportant in a decision-making context. In contrast, there may have been an inherent bias towards obtaining responses from more experienced members of CIEEM (Table 1) who were more likely to identify cases where there were serious outcomes.

It would be useful to obtain further information from the membership of CIEEM to gain a better understanding of how these potential sources of bias may have influenced the response rate and the conclusions that can be drawn from the questionnaire. It is acknowledged that the responses represent a relatively small proportion (approximately 3\%) of the total membership of CIEEM (Table 1), however the size of the target audience i.e. the sub-set of members who are actively involved in the conduct and interpretation of vegetation surveys is unknown. The estimate that approximately $20 \%$ of surveys contained misclassifications of vegetation types in both Phase 1 and NVC surveys (Figure 1) needs to be taken as a first estimate upon which to build further research.

Disagreements over habitat classifications are probably impossible to eliminate completely because all scientists are prone to subjectivity in decision making (Elliot and Resnik 2015) and vegetation is inherently variable and complex (Alexander and Millington 2000; Rodwell 2006). Demonstrating that there are practical consequences, however, can provide a mandate to improve standards of training and professional practice. Indeed, recognising the inherent variability in human behaviour is a first-step to advancing objective, repeatable and scientifically rigorous practice. A measure that would allow disagreements to be resolved more rapidly, and effectively, would be to ensure that data underpinning habitat classification decisions (in the form of Phase 1 Target Notes and NVC quadrat samples) is collected and reported in a more rigorous and consistent manner (Cherrill and McClean 1999a; Cherrill 2013a, 2014). The field manuals for Phase 1 and NVC allow a significant degree of flexibility in these aspects of the methodologies (JNCC 1993; Rodwell 2006). Moreover, this information (along with basic metadata such as the identity of the surveyors) is 
often not included within documents, such as site management plans and Environmental Statements, based on the original field survey reports (Cherrill 2007). In the absence of these metadata the reliability of mapping decisions is more difficult to assess and further field survey is more likely to be necessary to clarify the type of vegetation present (Cherrill 2013b). In the present study a majority of respondents to the questionnaire were in favour of introducing accreditation schemes for surveyors undertaking Phase 1 and NVC surveys. Several models are available. For example, an accreditation scheme is currently in place for surveyors undertaking River Habitat Surveys (RHS) (Environment Agency 2003). Completion of a training course, culminating in an assessment leading to accredited status, is mandatory if the survey is being conducted on behalf of the UK's Environment Agency (EA), but accreditation has also become the expectation among ecological consultants conducting RHS for other clients. Training and auditing are also central to the quality assurance processes used by UK agencies to assess water quality in accordance with the requirements of the EU Water Framework Directive (WFD) based on a range of ecological indicator taxa (Environment Agency 2009a, 2009b, Dines and Murray-Bligh 2000; Kelly 2013). For example, analysts assessing ecological status using diatoms must complete a training course and then submit their first three analyses for independent audit. To maintain accredited status diatomists must subsequently analyse at least 30 samples per year, pass an annual species identification ring-test, and demonstrate a commitment to on-going training (Kelly 2013). Analysts identifying freshwater macroinvertebrates for the UK agencies are also subject to external audit of their taxonomic determinations (Dines and Murray-Bligh 2000). In a panEuropean comparison, taxonomic errors for macroinvertebrate identification were lower in the UK's monitoring programme compared to within those of other EU states that lacked an external audit process. In addition, error rates in the UK declined after the auditing system was introduced (Murray-Bligh et al. 2006). These examples illustrate the measures that can be put in place where there are legislative drivers, and government agencies take a lead in developing, commissioning and/or carrying out the surveys. The situation with Phase 1 and $\mathrm{NVC}$ is different in that surveys are conducted by a wide range of independent consultancies, 
NGOs, and government agencies for a diversity of reasons and clients. Setting standards, providing training and monitoring performance are, however, activities where bodies such as CIEEM and the Botanical Society of the Britain and Ireland (BSBI) could take a stronger lead.

The BSBI working in collaboration with Manchester Metropolitan University, offers a test through which botanists can gain a Field Identification Skills Certificate (FISC) which shows their level of identification skills on a scale of 1 (beginner) to 5 (Professional) (BSBI 2015). Levels 3 and 4 are suggested as the minimum levels required to undertake Phase 1 and NVC surveys (Whild and Townsend 2007). The FISC is becoming established as the industry standard for assessing botanical survey skills, but it is the responsibility of clients who commission surveys to demand these levels of certification when awarding contracts.

Training courses in Phase 1 and NVC are available from providers, approved by CIEEM within their Continuing Professional Development (CPD) programme, but development of a nationally recognised qualification or accreditation scheme in collaboration with the BSBI and an institute of Higher Education may be a route through which CIEEM could more effectively raise professional standards for Phase 1 and NVC survey, especially if these were linked explicitly to Performance Indicators within CIEEM's Competency Framework (CIEEM 2006). There is evidence that more experienced botanists produce more complete species inventories (Rich and Smith 1996), and some evidence (albeit less welldocumented) that group training can reduce levels of inter-observer variation in vegetation mapping using Phase 1 and NVC (Cherrill 2013a). There is therefore a realistic prospect that introducing mandatory minimum levels of accreditation or certification for surveyors could provide a reliable and transparent method for employers and clients to judge the aptitude of surveyors, while simultaneously yielding improvements in professional practice.

\section{Acknowledgements}

Thanks are due to those who tested the pilot versions of the questionnaire and to all who took part in the survey. Particular thanks are due to CIEEM and especially Jason Reeves for 
running the survey online. Gill Kerby, Simon Leather, Keith Walters, Lucy Crockford and two anonymous referees gave constructive criticism which greatly improved earlier drafts of this paper. Any errors remain the responsibility of the author and the views expressed are not necessarily shared by CIEEM.

\section{References}

Alexander, R. and A. Millington. 2000. Vegetation mapping: from patch to planet. London: Wiley-Blackwell. 350pp.

Angold, P.G., Gurnell, A.M. and P.J. Edwards. 1996. "Locational errors in maps from environmental surveys and their implications for information extraction.” Journal of Environmental Management 47: 341-354.

Bernard, A.T.F., A. Gotz, S.E. Kerwath, and C.G. Wilke. 2013. "Observer bias and detection probability in underwater visual census of fish assemblages measured with independent double-observers." Journal of Experimental Marine Biology 443: 75-84.

Besse-Lototskaya, A., Verdonschot, P.F.M. \& J.A. Sinkeldam. 2006. "Uncertainty in diatom assessment: sampling, identification and counting variation.” Hydrobiologia 566: 247-260. Botanical Society of Britain \& Ireland. "Field Identification Certificates." BSBI. Accessed August $8^{\text {th }}$ 2015. www.bsbi.org.uk/field skills.html

Byron, H., J. Treweek, W. Sheate, and S. Thompson. 2000. "Road developments in the UK: an analysis of ecological assessment in environmental impact statements produced between 1993 and 1997." Journal of Environmental Planning and Management 43: 71-97.

Chartered Institute of Ecology and Environmental Management. 2006. “Competency

Framework." CIEEM. Accessed August $8^{\text {th }}$ 2015. http://www.cieem.net/competencyframework

Cherrill, A. 2007. "Reporting, archiving and sharing ecological survey data: do we need metadata standards? Developing best practice in survey and reporting." In Proceedings of IEEM's Spring Conference, $18^{\text {th }}$ April 2007, London, 59-62. Winchester: Institute of Ecology 
\& Environmental Management.

Cherrill, A. 2013a. "Repeatability of vegetation mapping using Phase 1 and NVC approaches: Implications for professional practice and surveyors' training requirements." Bulletin of the Chartered Institute of Ecology and Environmental Management - In Practice 81: 41-45.

Cherrill, A. 2013b. "Issues in survey reliability: Launch of a survey of CIEEM members." Bulletin of the Chartered Institute of Ecology and Environmental Management - In Practice 82: $35-36$.

Cherrill, A. 2014. "The occurrence, causes, and consequences of inter-observer variation in identification of Phase 1 and NVC vegetation types." Bulletin of the Chartered Institute of Ecology and Environmental Management - In Practice 86: 25-28.

Cherrill, A. and C. McClean. 1995. "An investigation of uncertainty in field habitat mapping and the implications for detecting land cover change." Landscape Ecology 10: 5-21. Cherrill, A. and C. McClean. 1999a. "Between observer variation in the application of a standard method of habitat mapping by environmental consultants in the UK." Journal of Applied Ecology 36: 989-1008.

Cherrill, A. and C. McClean. 1999b. "The reliability of Phase 1 habitat mapping in the UK: the extent and types of observer bias." Landscape and Urban Planning 45: 131-143. Cherrill, A. and C. McClean. 2000. "Lack of precision in mapping upland habitats and preliminary conservation assessments.” Aspects of Applied Biology 58: 167-172.

Cherrill, A.J. and C. McClean. 2001. "Omission and commission errors in the field mapping of linear boundary features: Implications for the interpretation of maps and organisation of surveys." Journal of Environmental Planning and Management 44: 331-343.

Clarke, R.T. and D. Hering. 2006. "Errors and uncertainty in bioassessment methods - major results and conclusions from the STAR project and their applications using STARBUGS.” Hydrobiologia 566: 433-439.

Diefenbach, D., D. Brauning, and J. Mattice. 2003. "Variability in grassland bird counts related to observer differences and species detection rates." The Auk 120: 1168-1179. 
Dines, R.A. and J. Murray-Bligh. 2006. "Quality assurance and RIVPACS.” In Assessing the Biological Quality of Fresh Waters - RIVPACS and Other Techniques, edited by J.F. Wright, W. Sutcliffe, \& M. Furse, 71-78. Ambleside: Freshwater Biological Association.

Drayson, K., and S. Stewart. 2103. "Ecological mitigation measures in English Environmental Impact Assessment.” Journal of Environmental Management 119: 103-110.

Elliot, K.C. and D.B. Resnik. 2015. "Scientific reproducibility, human error, and public policy." BioScience 65: 5-6.

Environment Agency. 2003. "River Habitat Survey in Britain and Ireland.” London:

Environment Agency.

Environment Agency. 2009a. "River macrophyte sampling: methodologies and variability." London: Environment Agency.

Environment Agency. 2009b. "Uncertainty in WFD assessments for rivers based on macroinvertebrates and RIVPACS.” London: Environment Agency.

Farmer, R.G., M.L. Leonard, and A.G. Horn. 2012. "Observer effects and avian-call-count survey quality: rare-species biases and overconfidence.” The Auk 129: 76-86.

Frederick, P., B. Hylton, J. Heath, and M. Ruane. 2003. "Accuracy and variation in estimates of large numbers of birds by individual observers using an aerial survey simulator." Journal of Field Ornithology 74: 281-287.

Fritsch, G. and A. Bruckner. 2014. "Operator bias in software-aided bat call identification." Ecology and Evolution 4: 2703-2713.

Furse, M., Hering, D., Moog, O., Verdonschot, P., Johnson, R., Brabec, K., Gritzalis, K., Buffagni, A., Pinto, P., Friberg, N., Murray-Bligh, J., Kokes, J., Alber, R., Usseglio-Polatera, P., Hasse, P., Sweeting, R., Bis, B., Szoszkiewicz, K., Soszka, H., Springe, G., Sporka, F. and I. Krno. 2006. "The STAR project: context, objectives and approaches.” Hydrobiologia 566: 3-29.

Garcia-Vazquez, E., D. Campo, and F. Juanes. 2012. "Species misidentification in mixed hake fisheries may lead to overexploitation and population bottlenecks." Fisheries Research 114: 52-55. 
Glasson, J., Therivel, R. and Chadwick, A. 2012. Introduction to Environmental Impact Assessment. London: Routledge.

Gray, I.M. and G. Edward-Jones. 1999. "A review of the quality of environmental impact assessments in the Scottish forest sector." Forestry 72: 1-10.

Gurnell, A.M., Angold, P.G. and P.J. Edwards. 1996. "Extracting information from river corridor surveys.” Applied Geography 16: 1-19.

Hasse, P., Murray-Bligh, J., Lohse, S., Pauls, S., Sundermann, A., Gunn, R. and Clarke, R.T. 2006. "Assessing the impact of errors in sorting and identifying macroinvertebrate samples." Hydrobiologia 566: 505-521.

Hasse, P., Pauls, S.U., Schindehütte, K. and A. Sundermann. 2010. "First audit of macroinvertebrate samples from an EU Water Framework Directive monitoring program: human error greatly lowers precision of assessment results." Journal of the North American Benthological Society 29(4):1279-1291.

Hearn, S., J. Healey, M. McDonald, A. Turner, J. Wong, and G. Stewart. 2011. “The repeatability of vegetation classification and mapping." Journal of Environmental Management 92: 1174-1184.

Hill, D., M. Fasham, G. Tucker, M. Shewry, and P. Shaw. 2005. Handbook of biodiversity methods. Survey, evaluation and monitoring. Cambridge: Cambridge University Press, Cambridge. 573 pp.

Hill, M.O. 1996. TABLEFIT version 1.0, for identification of vegetation types. Huntingdon: Institute of Terrestrial Ecology.

Hobbs, R.C. and J.M. Waite. 2010. “Abundance of harbor porpoise (Phocoena phocoena) in three Alaskan regions, corrected for observer errors due to perception bias and species misidentification, and corrected for animals submerged from view." Fisheries Bulletin 108: 251-267.

Institute of Environmental Assessment. 1995. Guidelines for baseline ecological assessment. London: E and F.N. Spon. 142pp. 
Institute of Ecology and Environmental Management. 2006. Guidelines for Ecological Impact Assessment in the United Kingdom. Winchester: Institute of Ecology and Environmental Management.

Institute of Ecology and Environmental Management. 2007. Rooting for a career in ecology or environmental management? Winchester: British Ecological Society/ Institute of Ecology and Environmental Management.

Institute of Ecology and Environmental Management. 2011. Ecological skills - Shaping the profession for the $21^{\text {st }}$ century. Winchester: Institute of Ecology and Environmental Management.

Jenkins, K.J. and B.F.J. Manly. 2008. "A double-observer method for reducing bias in faecal pellet surveys of forest ungulates." Journal of Applied Ecology 45: 1339-1348.

Joint Nature Conservation Committee 1993, revised 2007. Handbook for Phase 1 Survey - A technique for environmental audit. Peterborough: JNCC.

Kelly, M.G. 1997. "Sources of counting error in estimations of the trophic diatom index." Diatom Research 12: 255-262.

Kelly, M.G. 2013. "Building capacity for ecological assessment using diatoms in UK rivers." Journal of Ecology and Environment 36: 89-94.

Kahlert, M., Kelly, M.G., Albert, R-L., Almeida, S.F.P., Besta, T., Blanco, S., Coste, M., Denys, L., Ector, L., Frankova, M., Hlubikova, D., Ivanov, P., Kennedy, B., Marvan, P., Mertens, A., Miettinen, Picinska-Faltynowicz, J., Roseberry, J., Tornes, E., Vilbaste, S. and A. Vogel. 2012. "Identification versus counting protocols as sources of uncertainty in diatombased ecological status assessments." Hydrobiologia 695: 109-124.

Kolada, A., Ciecierska, H., Ruszcynska, J. and P. Dynowski. 2014. "Sampling techniques and inter-surveyor variability as sources of uncertainty in Polish macrophyte metric for lake ecological status." Hydrobiologia 737: 265-279.

Lotz, A. and C.R. Allen. 2007. "Observer bias in anuran call surveys." Journal of Wildlife Management 71: 675-679.

Malloch, A.J.C. 1998. MATCH version 2. Lancaster: University of Lancaster. 
MacDonald, A.J. 2010. "Testing the reliability of assessment of land management impacts on Scottish upland vegetation." Plant Ecology and Diversity 3: 301-312.

McClintock, B.T., L.L. Bailey, K.H. Pollock, and T.R. Simons. 2010. “Unmodeled observation error induces bias when inferring patterns and dynamics of species occurrence via aural detections." Ecology 91: 2446-2454.

Meek, P.D., K. Vernes, and G. Falzon. 2013. "On the reliability of expert identification of small-medium sized mammals from camera trap photos." Wildlife Biology in Practice 9: 1-19. Milberg, P., J. Bergstedt, J. Fridman, G. Odell, and L. Westerberg. 2008. "Observer bias and random variation in vegetation monitoring data." Journal of Vegetation Science 19: 633-644. Molianari-Jobin, A., M. Kery, E. Marboutin, P. Molinari, I. Koren, C. Fuxjager, C.

Breitenmoser-Wursten, et al. 2012. "Monitoring in the presence of species misidentification: the case of the Eurasian lynx in the Alps." Animal Conservation 15: 266-273.

Morris, P. and R. Thrivel. 2009. Methods of Environmental Impact Assessment. London: Routledge. 576pp.

Murray-Bligh, J., van der Molen, J. and P. Verdonschot. 2006. STAR deliverable No. 7. Audit of performance incorporating results of the La Bresse sampling and analysis workshop. Accessed August $8^{\text {th }}$ 2015. http://www.eu-star.at/pdf/Deliverable7.pdf

Pierce, B.A. and K.J. Gutzwiller. 2007. "Interobserver variation in frog call surveys.” Journal of Herpetology 41: 424-429.

Rich, T.C.G. \& Smith, P.A. 1996. "Botanical recording, distribution maps and species frequency." Watsonia 21: 155-167.

Rodwell, J.S. 1991-2000. British Plant Communities Volumes 1-5. CUP, Cambridge. Rodwell, J.S. (2006) National Vegetation Classification users' handbook. Peterborough: JNCC.

Scott, W.A. and C. Hallam. 2002. "Assessing species misidentification rates through quality assurance of vegetation monitoring." Plant Ecology 165: 101-115.

Shea, C.P., J.T. Peterson, J.M. Wisniewski, and N.A. Johnson. 2011. "Misidentification of freshwater mussel species (Bivalvia: Unionidae): contributing factors, management 
implications, and potential solutions." Journal of the North American Benthological Society 30: $446-458$.

Staniszewski, R., Szoszkiwicz, K., Zbierska, J., Lesny, J., Jusik, S. and R.T. Clarke. 2006.

"Assessment of sources of uncertainty in macrophyte surveys and the consequences for river classification." Hydrobiologia 566: 235-246.

Stevens, J., T. Blackstock, E. Howe, and D. Stevens. 2004. "Repeatability of Phase 1 habitat survey." Journal of Environmental Management 73: 53-59.

Sunde, P. and L. Jessen. 2013. "It counts who counts: an experimental evaluation of the importance of observer effects on spotlight count estimates." European Journal of Wildlife Research 59: 645-653.

Thackeray, S., Noges, P., Dunbar, M., Dudley, B., Skjelbred, B., Morabito, G., Carvalho, L., Phillips, G., Mischke, U., Catalan, J., de Hoyos, C., Laplace, C., Austoni, M., Padedda, B., Maileht, K., Pasztalenic, A., Jarvinen, M., Solheim, A.L. and R.T. Clarke. 2013. “Quantifying uncertainties in biologically-based water quality assessment: a pan-European analysis of lake phytoplankton community metrics." Ecological Indicators 29: 34-37.

Treweek, J., S. Thompson, N. Veitch, and C. Japp. 1993. "Ecological assessment of proposed road developments: a review of environmental statements." Journal of Environmental Planning and Management 36: 295-307.

Treweek, J. and S. Thompson. 1997. "A review of ecological mitigation measures in UK environmental statements with respect to sustainable development." International Journal of Sustainable Development and World Ecology 4: 40-50.

Westcott, D.A. and A. McKeown. 2004. "Observer error in exit counts of flying-foxes (Pteropus spp.)." Wildlife Research 31: 551-558.

Whild, S. and Townsend, S. 2007. "The botanical skills pyramid." Botanical Society of Britain and Ireland/University of Birmingham. Accessed August $8^{\text {th }} 2015$. http://www.bsbi.org.uk/Botanical_Skills_Pyramid.pdf 


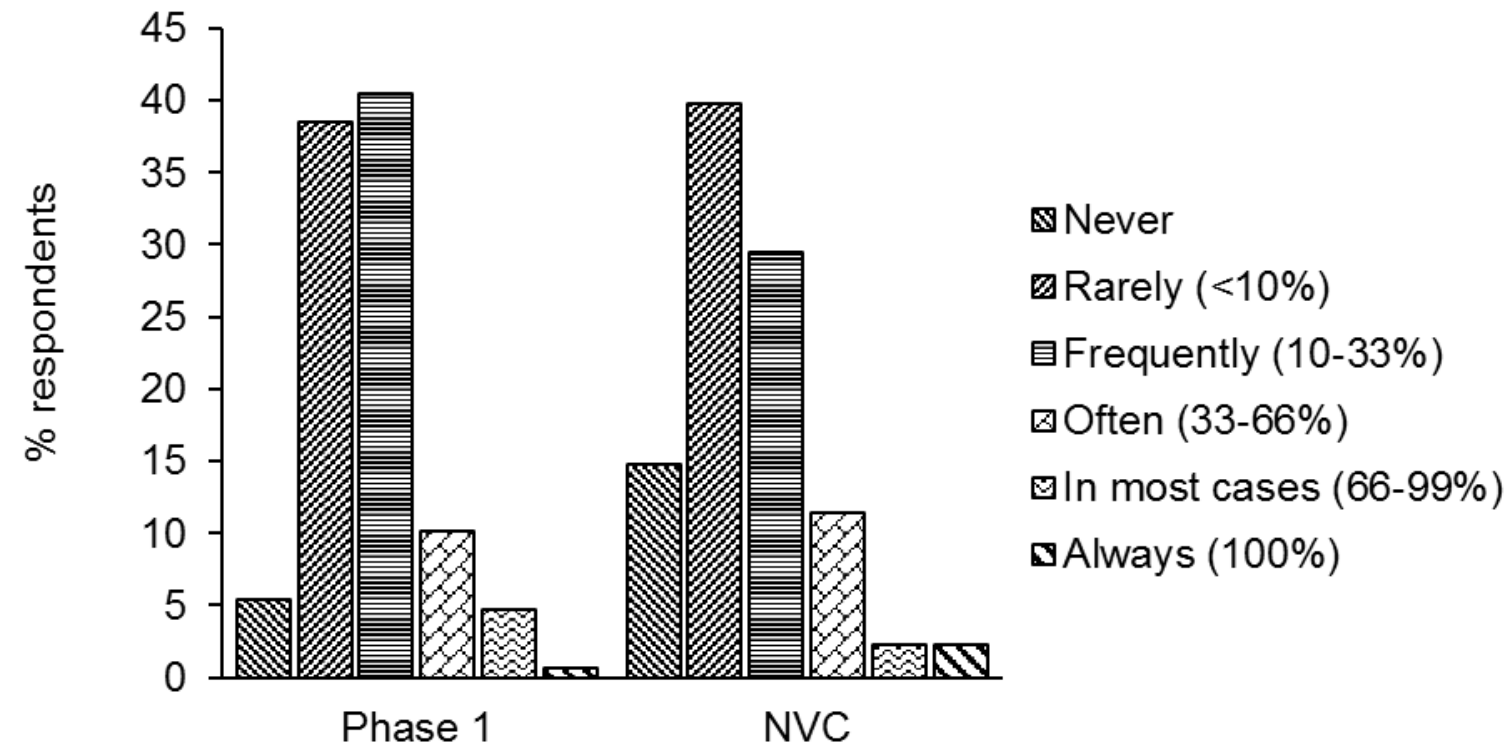

Figure 1. Respondents' perceptions of the frequency with which vegetation types were misidentified in surveys between 2009-2014 (Phase 1, n=148; NVC, n=88). 

Table 1. The characteristics of respondents to the questionnaire survey and the membership of the Chartered Institute of Ecology and Environmental Management (CIEEM) (for whom not all information was available).

\begin{tabular}{|c|c|c|c|c|c|c|c|c|}
\hline \multicolumn{3}{|l|}{ Employment sector } & \multicolumn{3}{|c|}{ Country of employment } & \multicolumn{3}{|c|}{ CIEEM membership grade } \\
\hline & Membership & Survey & & Membership & Survey & & Membership & Survey \\
\hline $\begin{array}{l}\text { Consultancy } \\
\text { Local Government }\end{array}$ & 64.2 & 77.7 & England & 78.3 & 75.7 & Fellow & 1.1 & 4.5 \\
\hline Authority & 6.7 & 6.7 & Wales & 6.0 & 7.5 & Full & 63.0 & 79.6 \\
\hline Statutory Agency & 13.1 & 6.7 & Scotland & 10.2 & 15.9 & Associate & 10.1 & 5.7 \\
\hline NGO & 10.0 & 3.2 & Northern Ireland & 1.0 & 0.0 & Graduate & 16.4 & 7.0 \\
\hline Industry & 2.0 & 1.9 & Republic of Ireland & 3.3 & 0.6 & Student & 6.9 & 0.6 \\
\hline \multirow[t]{3}{*}{ Research/HE } & 4.0 & 1.3 & Rest of world & 1.2 & 0.2 & Affliate & 2.3 & 0.6 \\
\hline & & & & & & Grade not stated & $\mathrm{n} / \mathrm{a}$ & 0.6 \\
\hline & & & & & & Not member & $\mathrm{n} / \mathrm{a}$ & 1.3 \\
\hline $\mathrm{N}$ & 3578 & 157 & $\mathrm{~N}$ & 5064 & 157 & $\mathrm{~N}$ & 5071 & 157 \\
\hline
\end{tabular}



Table 2. The contexts in which Phase 1 and NVC surveys were conducted for those reports perceived to contain misidentified vegetation types (based on responses provided in open textboxes).

\begin{tabular}{lcc}
\hline Context of survey reports* & \multicolumn{2}{c}{ \% of respondents ${ }^{\#}$} \\
\cline { 2 - 3 } & Phase 1 & NVC \\
\hline Ecological Impact Assessment (EcIA) as part of EIA & 54.0 & 62.5 \\
EA - related to development but not stated to be EcIA & 27.6 & 12.5 \\
EA - context not stated & 27.6 & 19.6 \\
EA for site Management Plan - context not stated & 6.9 & 26.8 \\
EA for site Management Plan - Designated Site & 1.2 & 3.6 \\
EA of Designated Site - context not stated & 2.3 & 5.4 \\
EA of Candidate Designated Site & 1.2 & 3.6 \\
Favourable Condition Assessment of Designated Site & 0 & 5.4 \\
Post-development Condition Monitoring & 2.3 & 5.4 \\
Large Scale Resource Inventory & 4.6 & 0 \\
EA contributing to assessment for PSS, CSH or CSR & 3.5 & 0 \\
EA for Biodiversity Offsetting & 1.2 & 1.8 \\
Number of respondents (N) & 87 & 56 \\
\hline
\end{tabular}

*EA - Ecological Appraisal, PSS - Protected Species Survey, CSH - Code for Sustainable Housing, CSR - Corporate Social Responsibility, BO - Biodiversity Offsetting.

\#Some responses included multiple contexts so that figures sum to $>100 \%$. 
Table 3. The consequences of perceived misidentifications of vegetation types in survey reports - responses to closed questions.

\begin{tabular}{llccccc}
\hline Consequence & \multicolumn{4}{c}{ \% of respondents } & N \\
\cline { 2 - 5 } & Method & Never & $\begin{array}{c}\text { In some } \\
\text { cases }\end{array}$ & Always & $\begin{array}{c}\text { Not } \\
\text { known }\end{array}$ \\
\hline Discussion with surveyor resolved & Phase 1 & 6.9 & 59.8 & 26.4 & 6.9 & 102 \\
issues & NVC & 8.1 & 56.5 & 29.0 & 6.5 & 62 \\
Further survey resolved issues & Phase 1 & 26.5 & 65.7 & 3.9 & 3.9 & 102 \\
& NVC & 24.6 & 67.2 & 4.9 & 3.3 & 61 \\
Negative impact on your organisation & Phase 1 & 35.9 & 51.5 & 6.8 & 5.8 & 103 \\
e.g. extra time and costs & NVC & 35.5 & 51.6 & 4.8 & 6.5 & 61 \\
Negative impact on clients/partners & Phase 1 & 56.9 & 25.5 & 1.0 & 16.7 & 102 \\
e.g. costs or delays & NVC & 55.7 & 31.1 & 3.3 & 9.8 & 61 \\
Negative outcomes for biodiversity & Phase 1 & 52.9 & 27.5 & 4.9 & 14.7 & 102 \\
e.g. net loss of biodiversity & NVC & 45.2 & 35.5 & 3.2 & 16.1 & 62 \\
\hline
\end{tabular}


Table 4. The consequences of perceived misidentifications of vegetation types - based on responses in open text-boxes.

\begin{tabular}{lcc}
\hline Perceived consequences & \multicolumn{2}{c}{ \% of respondents ${ }^{\#}$} \\
\cline { 2 - 3 } & Phase 1 & NVC \\
\hline Major issues identified: & 41.0 & 43.2 \\
Inaccurate site value applied & & \\
Solutions to resolve the problems: & 41.0 & 27.0 \\
Further survey required to resolve issues & 34.4 & 21.6 \\
Extra time required for discussion / revision of report & 8.2 & 8.1 \\
Extra time required to resolve issues - purpose not specified & & \\
Unavoided negative consequences: & 6.6 & 8.1 \\
Delays to project schedule/planning application & 6.6 & 5.4 \\
Net loss of biodiversity & 6.6 & 2.7 \\
Additional costs to self or client/partner stated explicitly & 4.9 & 5.4 \\
Inaccurate impact prediction & 4.9 & 5.4 \\
Caveats added to report to explain minor unresolved uncertainties & 4.9 & 2.7 \\
Poor final project design/late change in project design required & 3.3 & 8.1 \\
Inappropriate mitigation & 1.6 & 0 \\
Potential damage to own reputation & 61 & 37 \\
Number of respondents (N) & & \\
\hline H'Some respong ind
\end{tabular}

${ }^{\#}$ Some responses included multiple consequences so that figures sum to $>100 \%$. 